\title{
Proceeding
}

Supplementary Issue: Summer Conferences of Sports Science. $8^{\text {th }}$ International Workshop and Conference of the International Society of Performance Analysis of Sport (ISPAS), 11-13th of September 2019 (Budapest, Hungary) "Technology meets Practice and Science".

\section{Predictive performance analysis of players against training plan}

\author{
SHRINIVAS PRABHAKARRAO DESHPANDE 4 , DEEPA PRABHAKARRAO VAIDYA, NITIN VIJAYRAO \\ WANKHADA
}

Department of Computer Science and Technology, Degree College of Physical Education, Autonomous College, Amravati, Maharashtra, India

\begin{abstract}
Performance of a player in competitive sports is collective result of skill, physical and mental fitness, diet, training etc. Every human being is different and therefore personalization is required in every aspect. The wide use of computer system in different aspects of training and coaching makes it easy to generate and gather data in digital form. A powerful tool is required for analysis and interpretation of this data. The knowledge extracted from such data could be helpful in decision-making, system learning and automation. The training is requires to be individualized. This individualization helps to achieve maximum performance from each individual player. To ensure personalization it requires individual monitoring and evaluation, which is quite impossible without use of any tool. A system 'Swimming Coach Assistant' developed for predictive performance analysis of a player and assist coaches to extend personalized coaching to the player. The anthropometric measurements as suggested by the Heath-Carter method of Somatotyping of the player are used to describe the present morphological conformation of the player the nearest somatotypes of the players readily available in the system database are identify using distance formula (Somatotype Dispersion Distance). System suggests the best training plan previously identified and recorded by using data clustering approach. Otherwise, coach assign initial training plan based on his knowledge and expertise. The system provides a plot of performance of players in the practice session for the assigned training plan. A time series approach is use for fitting a straight line for the gathered performance data. This result provides a valuable feedback to the coaches to individualize the training activity and can predict the future performance if same training plan continues. Keywords: Personalized coaching; Swimming coach assistant; Predictive performance analysis.
\end{abstract}

\section{Cite this article as:}

Deshpande, S.P., Vaidya, D.P., \& Wankhada, N.V. (2019). Predictive performance analysis of players against training plan. Journal of Human Sport and Exercise, 14(5proc), S2455-S2462. doi:https://doi.org/10.14198//hse.2019.14.Proc5.62

\footnotetext{
Corresponding author. Department of Computer Science and Technology, Degree College of Physical Education, Autonomous College, Amravati, Maharashtra, India.

E-mail: shrinivasdeshpande68@gmail.com

Supplementary Issue: Summer Conferences of Sports Science. $8^{\text {th }}$ International Workshop and Conference of the International Society of Performance Analysis of Sport (ISPAS), 11-13 th of September 2019 (Budapest, Hungary).

JOURNAL OF HUMAN SPORT \& EXERCISE ISSN 1988-5202

(c) Faculty of Education. University of Alicante

doi:10.14198/jhse.2019.14.Proc5.62
} 


\section{INTRODUCTION}

In the era of digital world, the wide use of computer system makes it easy to generate and gather data in digital form. Use of computerized systems in different aspects of sports is generating tons of data every day and dumping in varied media. Amount of data kept in computer files and databases is growing at a phenomenal rate. The data is not only text or numbers but images, video, audio etc. i.e. multimedia data. Databases and data warehouses are the most common data repositories in the sports organizations.

There are many challenges in handling and analysing this data. Some major challenges are:

- $\quad$ Large size data repositories containing multidimensional data in different types and formats.

- $\quad$ Databases are centralized, distributed, web and mobile.

- Multimedia data gathered using varied tools and stored in different formats.

- $\quad$ Changing requirements and expectations of users.

- Retrieval of subset of data or derive inferences from the stored data is very difficult without using tools.

- $\quad$ Enhanced business needs.

To take complete advantage of data; data retrieval is simply not enough. Summarization of data, extraction of the essence of information, generation of useful knowledge are some advanced use of data (Pujari 2001). Due to enormous amount of data in the repositories, it is increasingly important to develop powerful tool for analysis and interpretation of the data. The knowledge extracted from such data could be helpful. In decisionmaking, system learning and automation (Pei, Han and Kamber 2011) which is the need of time.

Performance of any player in competitive sports is collective result of skill, physical and mental fitness, diet, training etc. (Modak and Debnath 2011). Every human being is different and therefore personalization is required in every aspect (Modak and Debnath 2011).

Traditionally sports knowledge has been believed to be available with experts - the scouts, coaches, and managers. Sports organizations have now begun to realize that there is a wealth of knowledge contained in their data. The coaches who are in-charge of the team on the playing surface, and the general managers, who are in-charge of drafting or signing players, try to retrieve meaning and insight from the wealth of data for the scouts to evaluate future prospects and talent. Most in-house statisticians and analysts are helping the sports organization to gain valuable information from the data available in sports domain.

Hidden knowledge in the data gathered in Sports activity is required to be understood by the coaches and trainers, to apply it correctly to the training process of a particular sport. (Modak and Debnath 2011) The Sports training is based upon many factors like: efficiency, endurance, skills, body types, socio-psychological parameters, nutrition, etc. (Modak and Debnath 2011; Uppal 2018) The training requires to be individualized. This individualization helps to achieve maximum performance from each individual player.

In the competitive sports, players' performance mainly depends upon the physical fitness, skill and training of the player. The skill and training plays vital role in performance and personalization is required in this aspect. To ensure personalization it requires individual monitoring and evaluation, which is quite impossible without use of any tool.

We have developed a system 'Swimming Coach Assistant' for predictive performance analysis of a player and assist coaches to extend personalized coaching to the player. 


\section{SYSTEM ARCHITECTURE AND METHODOLOGY}

As the personalized coaching and monitoring is required for performance enhancement of players, a computerized system developed which assist coaches to plan personalized training programme, monitor the performance of players during training sessions, assist to select best possible training plan and predict the performance of player for assigned training plan and coaching session. The system developed for swimming and named as 'Swimming Coach Assistant', the system architecture is as given below.

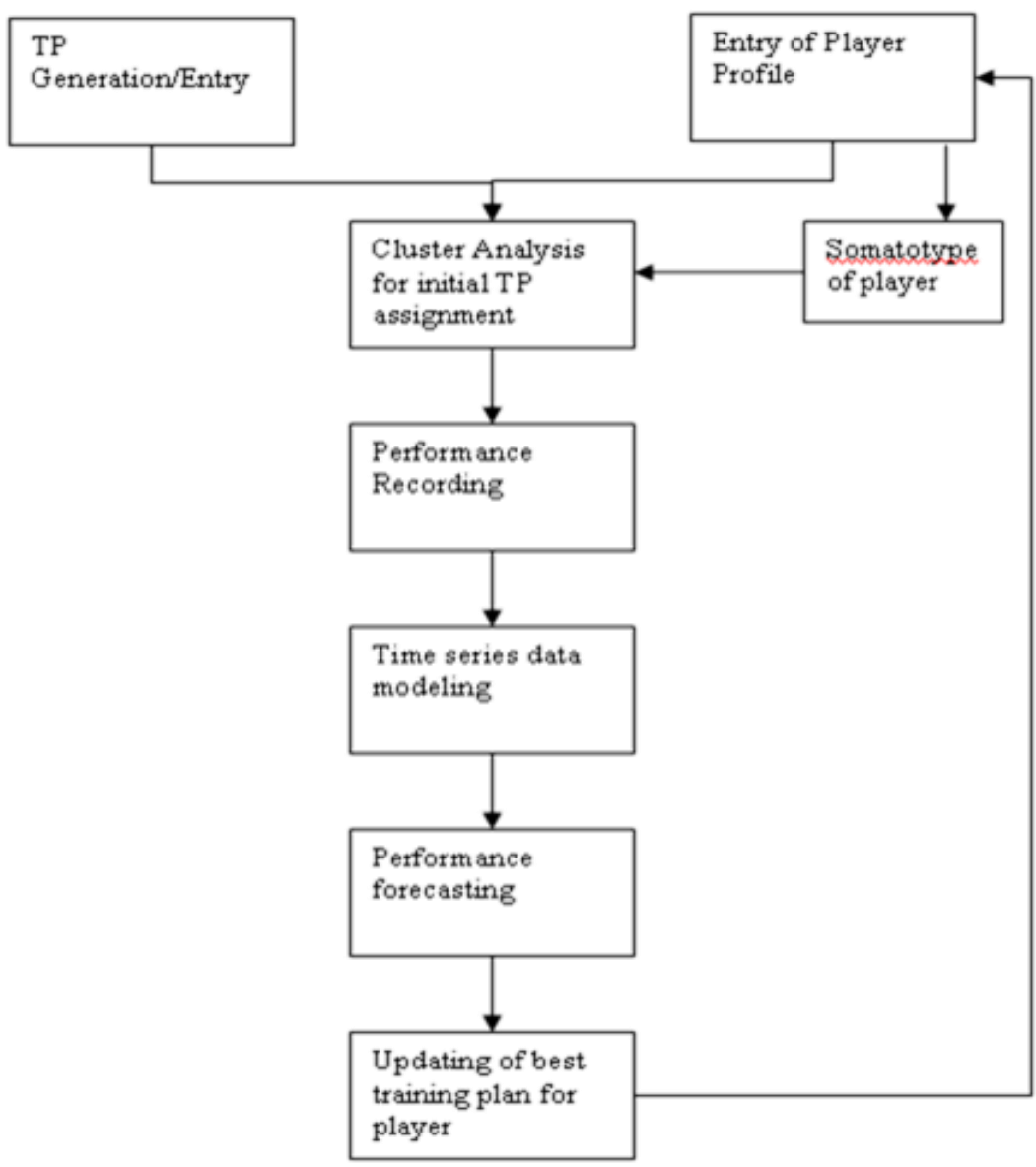

Figure 1. Flowchart of the system.

This system has four main processes, Entry of Players' Profile and Training Plans, Assigning the training plan to player, Performance entry and analysis, updating best training plan for player. System is developed in .Net framework and available an interface to connect touch panel for accurate auto capturing of swimmers' performance.

Coaches enter anthropometric measurements as suggested by the Heath-Carter method of Somatotyping of the player (Singh and Mehta 2009; Norton and Olds 2002). Somatotypes describe the present morphological conformation and have three numeral ratings representing Endomorph (fatness in physiques), Mesomorph (musculo-skeletal development) and Ectomorph (individual physique based on height-weight ratio). System generates a triplet representing somatotype of the player and compares it with somatotype of existing players the nearest somatotypes are identify using distance formula (Somatotype Dispersion Distance) (Singh and 
Mehta 2009). If near similar somatotype available in the database, system suggest the best training plan previously identified and recorded. Otherwise, coach assign initial training plan based on his knowledge and expertise. Data clustering using 'Nearest Neighbour' for near similarity for assignment of training plan executed.

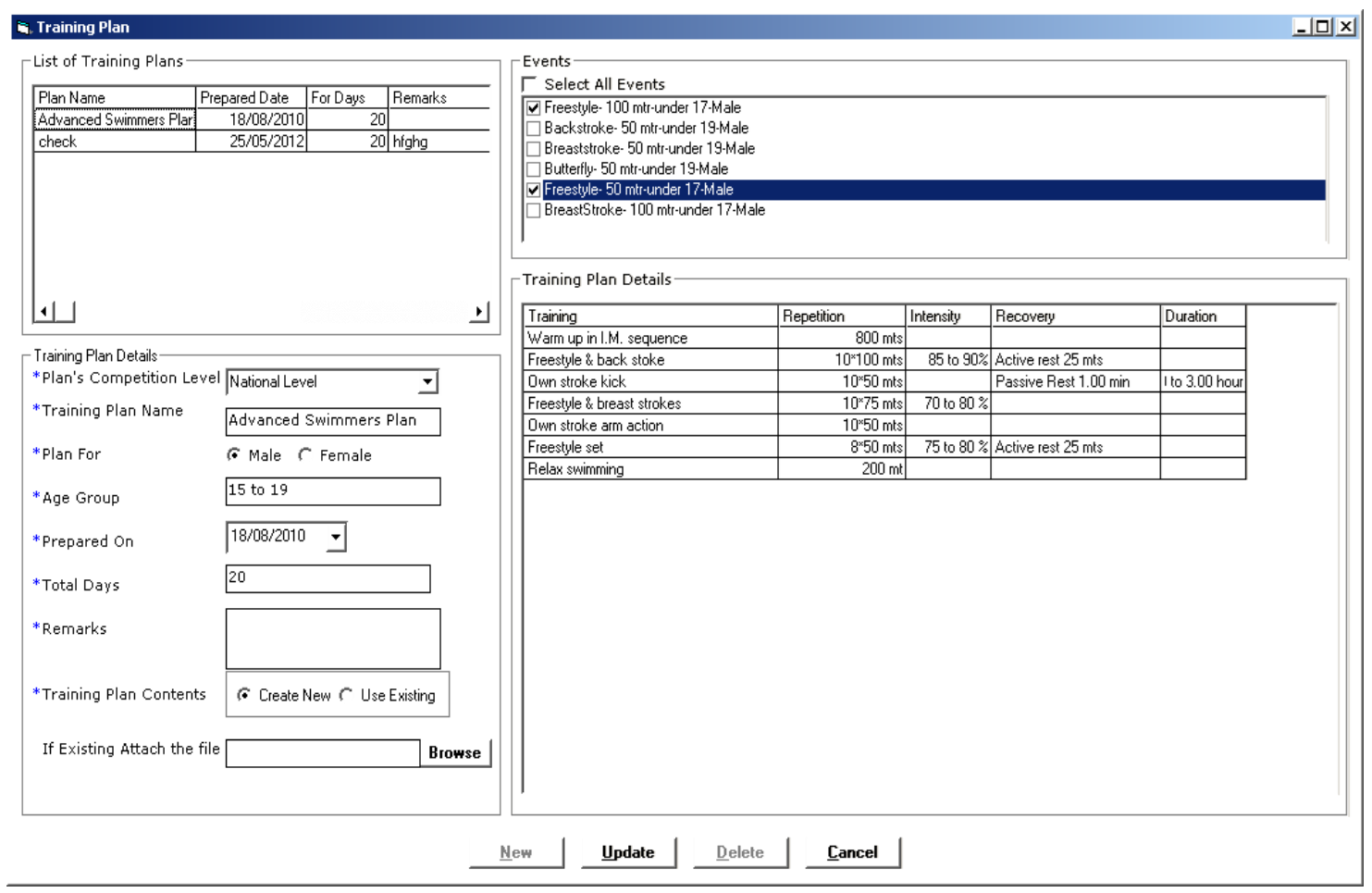

Figure 2. Entry form for Training Plan.

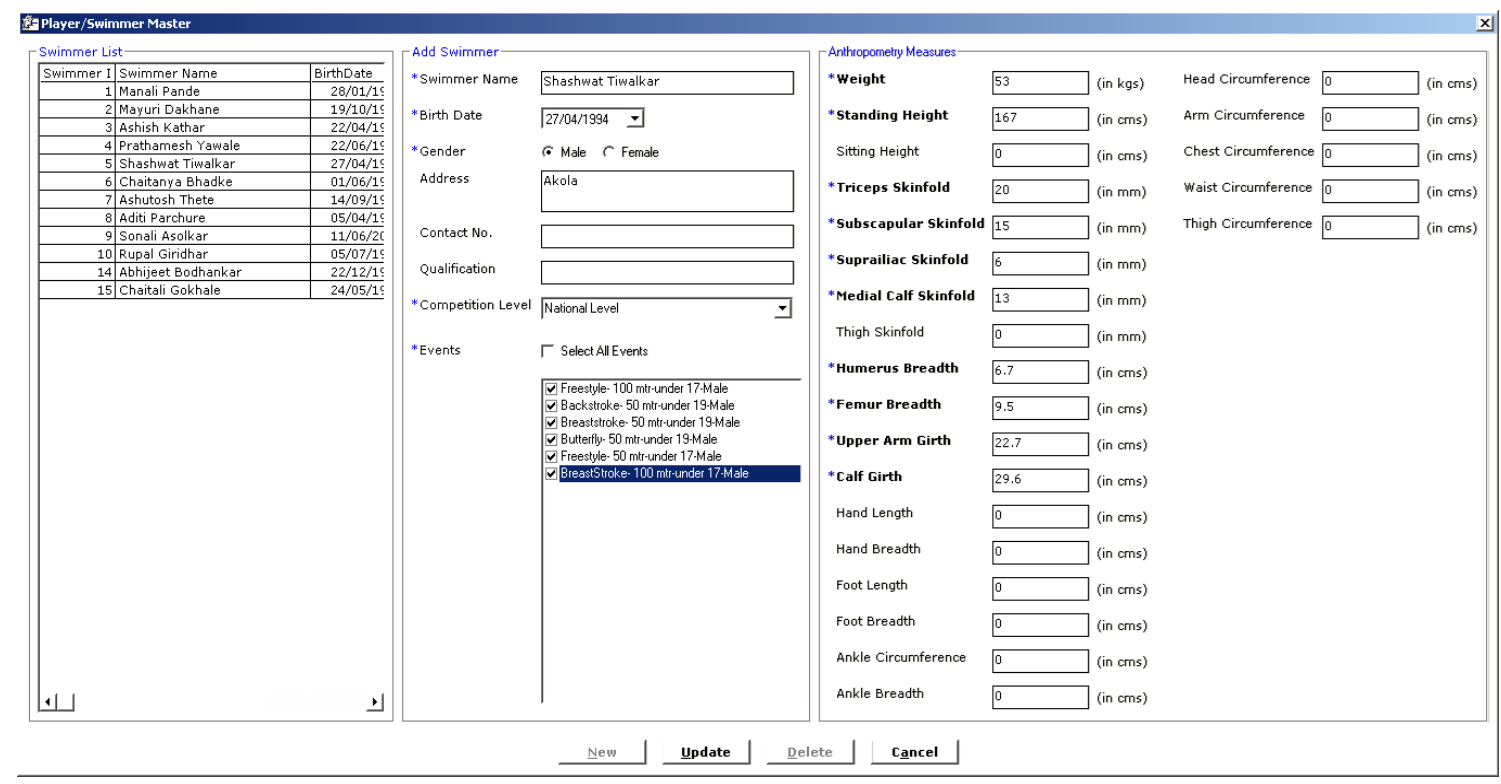

Figure 3. Entry form for Anthropometric Measurement. 
Swimmer's List with Anthropometry Measurements

\begin{tabular}{|c|c|c|c|c|c|c|c|}
\hline Swimmer Id & 5 & Weight & 53.00 & Hand Length & 0.00 & Medial Calf Skinfold & 13.00 \\
\hline \multirow[t]{2}{*}{ Swimmer Name } & Shashwat Tiwalkar & Standing Height & 167.00 & Hand Breadth & 0.00 & Humerus Breadth & 6.70 \\
\hline & & Sitting Height & 0.00 & Foot Length & 0.00 & Femur Breadth & 9.50 \\
\hline Birth Date & $27,04 / 1994$ & Head Circ unference & 0.00 & Foot Breadth & 0.00 & Endomorphy & 4.26 \\
\hline M/F & M & Arm Circ umference & 0.00 & Ankle Circumference & 0.00 & Mesomorphy & 2.53 \\
\hline \multirow[t]{3}{*}{ Address } & Akola & Chest Circ unference & 0.00 & Ankle Breadth & 0.00 & Ectomorphy & 3.96 \\
\hline & & Waist Circ umference & 0.00 & Thigh Skinfold & 0.00 & Somatotype Rating & $43-4$ \\
\hline & & Thigh Circ unference & 0.00 & Triceps Skinfold & 20.00 & & \\
\hline \multirow{2}{*}{\multicolumn{2}{|c|}{ Qualification }} & Upper Arm Length & 22.70 & Subsc apular Skinfold & 15.00 & & \\
\hline & & Calf Girth & 29.60 & Suprailiac Skinfold & 6.00 & & \\
\hline \multicolumn{8}{|l|}{ Practices Events } \\
\hline \multicolumn{8}{|c|}{ Freestyle-100Mtrs -under 17-Male } \\
\hline \multicolumn{8}{|c|}{ Backstroke-50Mtrs -under 19-Male } \\
\hline \multicolumn{8}{|c|}{ Breaststroke-50Mtrs -under 19-Male } \\
\hline \multicolumn{8}{|c|}{ Butterfly-50Mtrs -under 19-Male } \\
\hline \multicolumn{8}{|c|}{ Freestyle-50Mtrs -under 17-Male } \\
\hline BreastStroke-100M & Is -under 17-Male & & & & & & \\
\hline
\end{tabular}

Figure 4. Evaluation of Somatotype Rating.

Systems Suggestion for assigining Training Plan on Performance Evaluation of previous Swimmer's

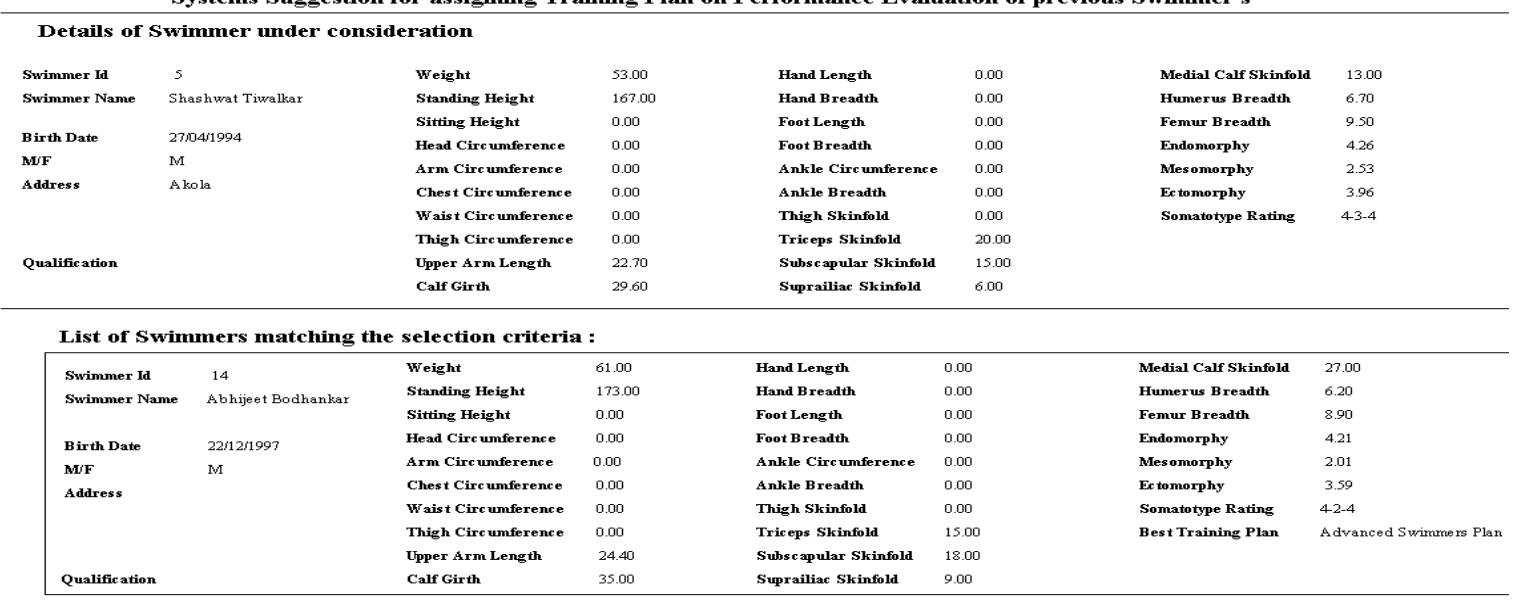

System Suggest following Training Plan based on previous Performance Evaluation

Training Plan (s)

Advanced Swimmers Plan

Figure 5. System suggest a training plan for player based on anthropometric measurements.

Once the training plan assign to the player, it will be record in the system. The entry of performance of the player during the practice session shall be automatic through an interface available with the system connected to the touch panel. The best performance of every practice day is use for further analysis. Following is the entry form for performance recording. 


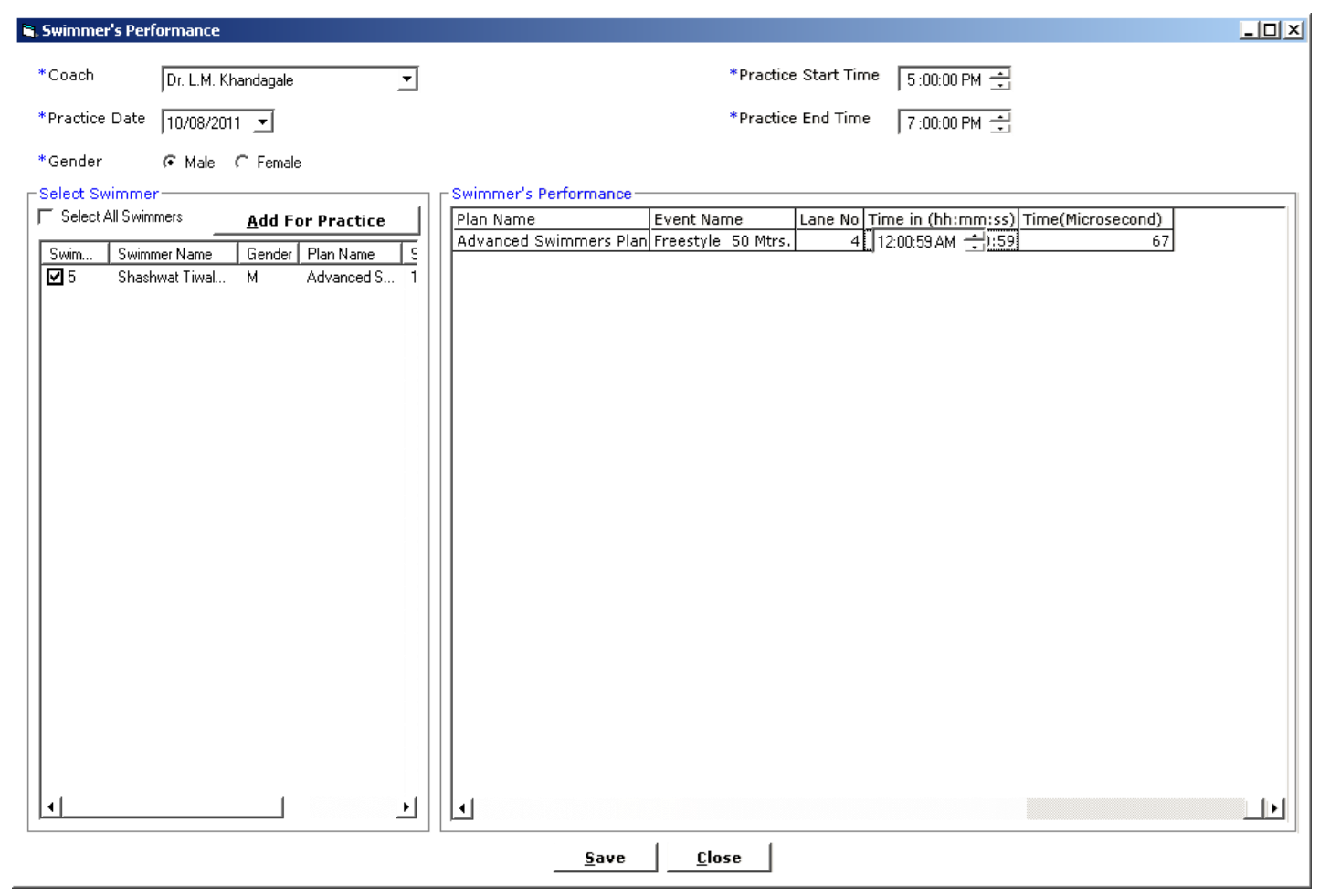

Figure 6. Form for recording the performance of the swimmers.

\section{Graphical Representation of Swimmers Performance against Plan and Event}

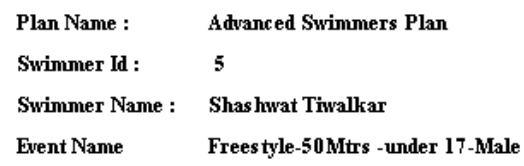

\section{Performance Graph}

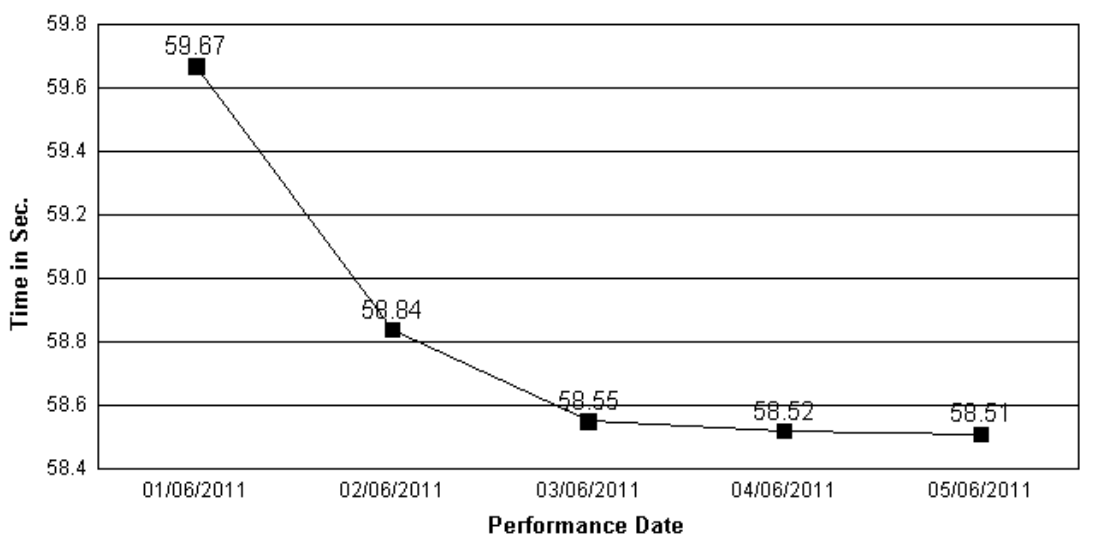

Figure 7. Graphical presentation of player's best performance day wise. 
Coaches can plot the graph of player's performance over a specified period. Coaches can analyse the performance and feedback player accordingly. System uses the Time-Series approach Linear Regression for fitting a straight line for the performance data. Using least-square method system fits a straight line, evaluates the values for 'Slope' and for 'Constant'. This is a classification method, which is use for prediction. With the help of values evaluated for 'Slope' and 'Constant' the straight line can be, extend for prediction of the further performance if the same training plan continues. Coaches can use this feedback and make decision, whether to continue the same training plan or assign a new one.

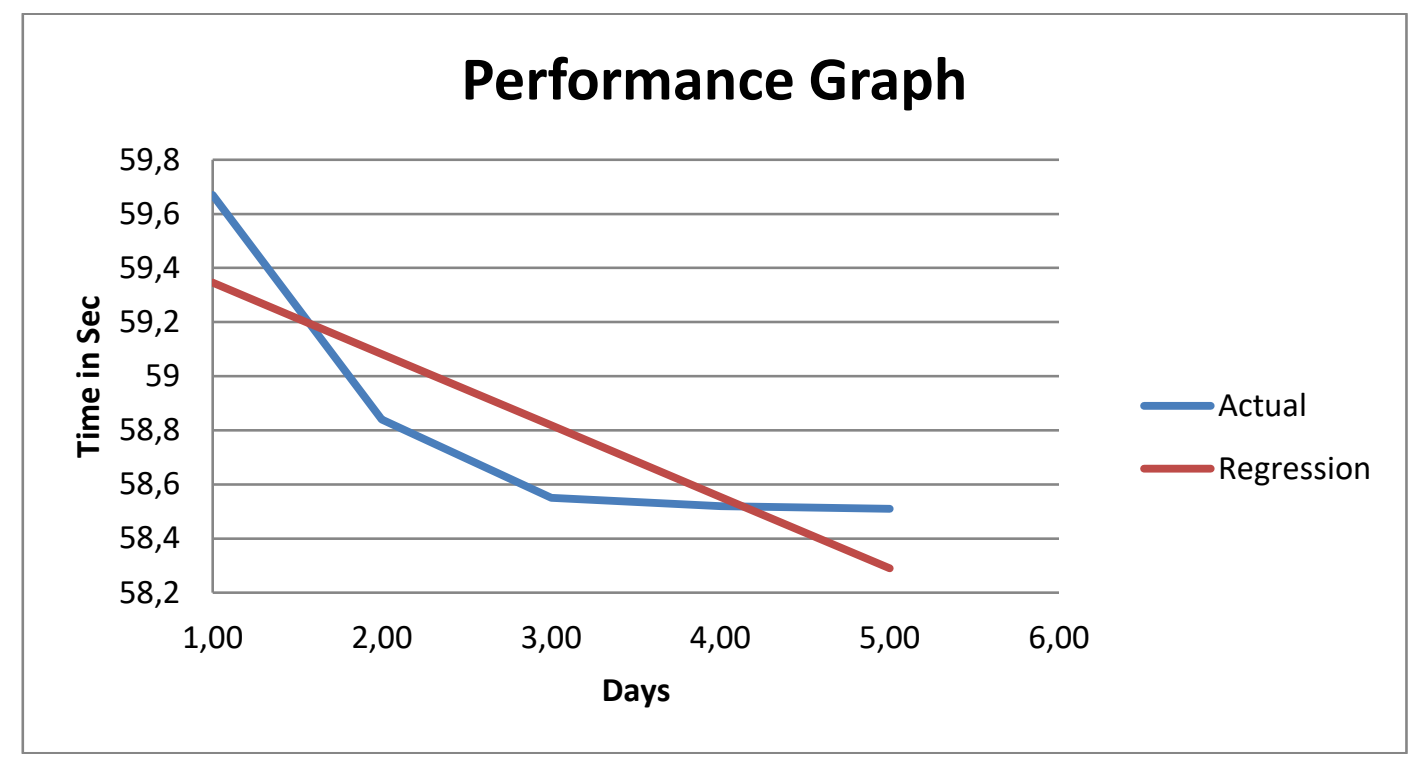

Figure 8. Linear regression of performance data showing actual performance and regression.

\section{RESULTS}

For better visualization and understanding, system generates graphical output. The result gives performance analysis of player against the applied training plan. System also suggests the best suitable training plan for the player based on anthropometric parameters. Time series analysis (linear regression) gives prediction of performance on the day of competition if the existing training plan continues.

\section{DISCUSSION AND CONCLUSION}

Every player based on his physical, mental, social and economic status need to be treated independently. A common approach during training/coaching badly affects performance of player. Personalized training/coaching/monitoring is difficult without tools for performance analysis. This system assists the coaches in administering and monitoring the training/coaching activity. As a part of future scope one can integrates other aspects like: diet plan, conditioning sessions, medication and counselling sessions etc. which may impact the players' performance in the competitions.

\section{REFERENCES}

Modak, P., Debnath, K. K., (2011), Science of Sports Training: A Comprehensive Approach. New Delhi, New Delhi: Sports Publication. 
Norton, K., Olds, T. (2002), Anthropometrica, Sydney, Australia: UNSW Press Ltd.

Pei, J., Han, J., Kamber, M., (2011), Data Mining Concepts and Techniques, India, Elsevier.

Pujari, A., (2001), Data Mining Techniques, India, University Press.

Singh, S. P., Mehta, P. (2009), Human Body Measurements: Concepts and Applications. New Delhi, New Delhi: PHI Learning Private Limited.

Uppal, A. K., (2018), Scientific Principles of Sports Training. Daryaganj, New Delhi: Friends Publications.

\section{(c) (i) ()}

This work is licensed under a Attribution-NonCommercial-NoDerivatives 4.0 International (CC BY-NC-ND 4.0). 